\title{
Editorial
}

\section{Cultivando nossa experiência de leitores: resenhas bibliográficas}

\section{Cultivating our readers' experience: \\ critical reviews}

Marta Regina de Leão D'Agord*1

Em 2020, completamos 22 anos de publicação contínua da nossa Revista Latinoamericana de Psicopatologia Fundamental (RLPF) e, com o número atual, alcançamos 92 edições trimestrais. A revista foi lançada no III Congresso Brasileiro de Psicopatologia Fundamental, em 1998, com o objetivo de divulgar as pesquisas em psicopatologia fundamental. Manoel Tosta Berlinck, no editorial do segundo número, anunciava que seriam destacados os trabalhos daqueles que, dentro ou fora das instituições universitárias, se dedicavam à investigação sistemática em psicopatologia. Cabe reconhecer o trabalho editorial de Manoel, que então liderava a Rede Universitária de Pesquisa em Psicopatologia Fundamental, futura Associação Universitária de Pesquisa em Psicopatologia Fundamental (AUPPF).

No primeiro número, a Revista apresentava três seções: Editorial, Artigos e Resenhas. O acolhimento da heterogeneidade,

${ }^{* 1}$ Universidade Federal do Rio Grande do Sul - UFRGS (Porto Alegre, RS. Brasil). 
característica da psicopatologia, logo fomentaria novas seções: Entrevista, História da Psiquiatria, Observando a Medicina, Observando a Psiquiatria, Saúde Mental, Clássicos da Psicopatologia, Primeiros Passos, Movimentos Literários, História da Psicanálise, Epistemologia da Psicopatologia, Literatura, Arte, Cultura. Algumas descontinuaram, outras foram renomeadas.

A seção Resenhas da $R L P F$ está ativa desde o primeiro número, mas passou por modificações em seu formato e nomeação. A experiência de leitura das primeiras resenhas publicadas pela $R L P F$ é comparável à abertura de uma cápsula do tempo. Convido o leitor a me acompanhar. Já no segundo número da $R L P F$, a seção Resenhas foi desdobrada em duas seções, Resenhas de Livros e Resenhas de Artigos. Essa última, então editada por Mario Eduardo Costa Pereira, cumpria a missão de manter o leitor da revista atualizado com as pesquisas internacionais na área da psicopatologia. Essa proposta estava patente já no primeiro artigo resenhado: um relato de pesquisa publicado naquele mesmo ano no American Journal of Psychiatry. O autor do artigo era ninguém menos que Eric Kandel, cientista com familiaridade com a psicanálise praticada nos Estados Unidos e que viria a ser premiado com o Nobel dois anos depois, pelas suas pesquisas na área da memória. Essa seção primava por divulgar o teor das publicações recentes, acessíveis apenas em língua inglesa e que na época ainda não estavam disponíveis na internet, tais como: American Journal of Psychiatry, Science, Scientific American, British Journal of Psychiatry, New England Journal of Medicine, Archives of General Psychiatry, Journal of Forensic Psychiatry On-Line, Psychosomatics, Lancet, British Journal of Psychiatry. Artigos veiculados em espanhol e língua portuguesa também foram resenhados: entre os quais Acheronta, Revista de Psicologia da PUC-Rio e Revista de Psiquiatria Clínica.

A seção Resenha de Livros seguiu apresentando, a cada número, em média duas resenhas dos últimos lançamentos na área. Em 2007, as principais revistas internacionais estavam acessíveis via web e a seção Resenhas de Artigos descontinuou. Em 2008, nossa revista, até então disponível no portal da AUPPF, foi incluída na coleção SciELO de periódicos. Entre 2008 e 2010, a seção Resenha de Artigos foi retomada em novo formato. A nova proposta consistia em um comentário crítico que encadeava, em torno de um tema comum, quatro ou mais artigos publicados em revistas nacionais e internacionais. Os artigos eram escolhidos em função da importância dos veículos, da qualidade de seus autores e da pertinência do conteúdo para o foco da revista.

Guilherme Gutman (2008) assim apresentava a seção: 


\section{EDITORIAL}

Que esta seção possa funcionar como "um bom colega de profissão e de interesses"; útil, por exemplo, na escolha do que ler e do que não ler, em tempos de volumes inabordáveis de artigos e periódicos à disposição. [...] A tarefa principal dessa seção é a de convocar o leitor a participar do jogo: experimentem os textos, lancem-se ao risco, inerente à leitura, que é o de interpretar, o de refletir e o de elaborar o que foi lido. (Gutman, 2008, pp. 515-516)

A função crítica dessa seção seguiu sendo destacada com a colaboração de Sonia Leite a partir de 2013. É assim que, em 2015, a seção Resenhas foi renomeada Resenhas Bibliográficas. Ainda em 2015, Sonia Leite redigiu uma orientação metodológica para a redação de resenhas críticas. Essa orientação está publicada resumidamente em Instruções aos autores da $R L P F$. Os comentários do autor da resenha ganham relevância. Espera-se de uma resenha crítica, uma análise, um exame e um julgamento sobre um livro ou escrito recente. Desse modo, o leitor obterá uma orientação para suas escolhas de leitura.

A resenha crítica, preconizada pela seção Resenhas Bibliográficas, objetiva julgar a relevância de uma publicação recente, sem esquecer de cultivar a delicadeza do estilo, despertando o interesse de leitura.

\section{Referências}

Berlinck, M. T. (1998). Editorial. Revista Latinoamericana de Psicopatologia Fundamental, 1(1), 7-8. Recuperado de: $<$ https://doi.org/10.1590/141547141998001001>.

Gutman, G. (2008). Um companheiro de leituras. Revista Latinoamericana de Psicopatologia Fundamental, 11(3), 514-516. Recuperado de: <https://doi. org/10.1590/S1415-47142008000300017>.

Citação/Citation: D’Agord, M. R. de L. (2020, mar.). Editorial. Cultivando nossa experiência de leitores: resenhas bibliográficas. Revista Latinoamericana de Psicopatologia Fundamental, 23(1), 11-12. http://dx.doi.org/10.1590/1415-4714.2020v23n1p11-1

Editoras/Editors: Profa. Dra. Ana Maria Galdini R. Oda e Profa. Dra. Sonia Leite 
Recebido/Received: 10.01.2020 / 01.10.2020 Aceito/Accepted: 10.01.2020 / 01.10.2020

Copyright: C 2009 Associação Universitária de Pesquisa em Psicopatologia Fundamental/ University Association for Research in Fundamental Psychopathology. Este é um artigo de livre acesso, que permite uso irrestrito, distribuição e reprodução em qualquer meio, desde que o autor e a fonte sejam citados / This is an open-access article, which permits unrestricted use, distribution, and reproduction in any medium, provided the original authors and sources are credited.

\section{Marta Regina de Leão D’Agord}

Psicóloga; Mestre em Filosofia; Doutora em Psicologia; Professora do Departamento de Psicanálise e Psicopatologia e Programa de Pós-Graduação em Psicanálise: Clínica e Cultura do Instituto de Psicologia da Universidade Federal do Rio Grande do Sul UFRGS (Porto Alegre, RS, Br). Pesquisadora Produtividade CNPq (Brasília, DF, Br). Editora Associada da Seção Resenhas Bibliográficas desde 2018.

Rua Riveira 600

90670-160 Porto Alegre, RS, Br

marta.dagord@ufrgs.br

https://orcid.org/0000-0003-0379-5323

This is an open-access article, which permits unrestricted use, distribution, the original authors and sources are credited. 